\title{
Transfer of Listeria monocytogenes between Abiotic Surfaces under Different Weights
}

\author{
Hai Yen Lee, Lay Ching Chai, Nor Ainy Mahyudin, Mitsuaki Nishibuchi, and Radu Son
}

Received July 19, 2013; revised December 23, 2013; accepted January 7, 2014; published online August 31, 2014

(C) KoSFoST and Springer 2014

\begin{abstract}
Cross contamination of Listeria monocytogenes from two different surfaces (plastic wrappers and stainless steel coupons) was simulated using a series of different weights. Enumeration of transfer was based on surface bacterial counts of biofilm stained surfaces. Direct contact between 2 surfaces has a constant rate of transfer that is independent of the pressure applied. This is the first report on the study of cross contamination between surfaces using pressure to illustrate transfer of bacteria in a food processing line.
\end{abstract}

Keywords: Listeria monocytogenes, biofilm formation, stainless steel, plastic wrappers, pressure

\section{Introduction}

Listeria monocytogenes is a recognized foodborne pathogen with the ability to cause severe health problems, particularly for high risk individuals. Some of the diseases caused by $L$. monocytogenes are bacteremia, meningitis, and may lead to abortion. Human listeriosis is reportedly increasing in several countries, including England and Wales (1), and in Europe (2). Reports from 2000-2004 showed an upsurge in the disease incidence in England and Wales among the

Hai Yen Lee $(\bowtie)$, Nor Ainy Mahyudin, Radu Son

Food Safety Research Centre (FOSREC)/Department of Science, Faculty of Food Science and Technology, Universiti Putra Malaysia, 43400 Serdang, Selangor Darul Ehsan, Malaysia

Tel: +603-8946-8495; Fax: +603-8942-3552

E-mail: leehaiyen@gmail.com

Lay Ching Chai

Institute of Biological Sciences, Faculty of Science Building, Universiti of Malaya, 50603 Kuala Lumpur, Malaysia

Mitsuaki Nishibuchi

Center for Southeast Asian Studies, Kyoto University, Kyoto 606-8501, Japan elderly population with an unexplainable cause, due to a limitation of knowledge in the epidemiology of listeriosis. The dispersed form of the disease suggests that the increase in human listeriosis may not be due to common exposure to a single food source (1). In Denmark, a report for 2009 also showed a rise in the number of cases of listeriosis (3). The dire health consequences caused by L. monocytogenes are known to be $99 \%$ related to consumption of contaminated foods (4). The common isolated serotypes of $L$. monocytogenes are $1 / 2 \mathrm{a}$ and $4 \mathrm{~b}$; however, serotype $1 / 2 \mathrm{a}$ is usually found in food isolates while $4 \mathrm{~b}$ is usually found in outbreaks (5).

Food contamination with L. monocytogenes has been reported frequently in food industries and generally occurs after thermal processes, and may be related to re-contamination of a food product (6). It has been acknowledged that $L$. monocytogenes cannot completely be eradicated because it is commonly found in the environment $(6.1 \%)$ and in food processing factories (12.8\%) (7). Higher incidences of $L$. monocytogenes in food processing facilities may be attributed to the ability of the bacterium to form a biofilm (8) that increases survival and persistence $(9,10)$.

Biofilms are commonly a source of food contamination in industrial facilities because food residues that accumulate on surfaces can act as a continuous culture system for propagation of microorganisms on the surface (11). A biofilm is initiated when attachment of a bacterium takes place, followed by formation of microcolonies and subsequent maturity of the microcolonies into a biofilm structure constructed of extrapolymeric substances. It was found that sessile cells in a biofilm are more resistant to disinfectants than planktonic cells, especially after attachment to a surface (12). Formation of biofilms on different surfaces has been widely documented over the years, including stainless steel, glass, polypropylene, and rubber in food processing plants (13). Surface roughness of a stainless steel material can have an effect on the degree of bacterial 
adherence. Arnold and Bailey (14) reported 3 different types of finishing treatments on stainless steel for poultry processing tested for an affinity of bacterial attachment wherein it was proposed that food safety can be improved by using materials that are resistant to bacterial contamination. Electropolished stainless steel with the least rough surface has fewer cell attachments and biofilm formations than other surfaces tested. However, Rodriguez et al. (15) reported that a cocktail $L$. monocytogenes strains showed no difference in adhesion values between electropolished stainless steel and mechanically polished stainless steel, and reported that electropolishing stainless steel does not increase the degree of food sanitation over mechanically finished stainless steel.

Food contact surfaces are of great concern because contamination of food processing surfaces, such as conveyor belts and packaging surfaces, with high levels of microbes, such as L. monocytogenes (16) increases the risk of cross contamination. Contact surfaces have been recognized as critical control points for food safety assessments. Reports regarding survival of $L$. monocytogenes on surfaces such as conveyor belt materials (17) highlight the importance of investigating the nature of cross contamination.

Factors affecting biofilm dispersal that lead to cross contamination include temperature, oxygen levels, $\mathrm{pH}$, specific compounds, food residues, and antimicrobial additives on the surfaces (18-20). Transfer of contaminants to food products occurs through contact and via pressure on a biofilm. No studies have reported the transferrable amounts of cells when food products come into contact with biofilm-contaminated surfaces with consideration of applied weight. Therefore, this study focuses on the effect of weight in transfer of biofilm bacteria from stainless steel coupons. Transfer of bacteria from the L. monocytogenes ATCC 19112 biofilm (serotype 1/2 a-common in food) formed on stainless steel was enumerated for polypropylene plastic wrappers under different weights.

\section{Materials and Methods}

Bacterial strains and culture preparation L. monocytogenes ATCC 19112 (serotype 1/2a) was used. A preculture of $L$. monocytogenes was obtained after a sample of the organism was inoculated into tryptic soy broth (Merck, Darmstadt, Germany) and allowed to grow in an incubator shaker (MaxQ 4000; Barnstead Lab Line, Dubuque, IA, USA) for $12 \mathrm{~h}$ at $37^{\circ} \mathrm{C}$ until the stationary phase was reached, as determined using spread plating of the culture of a consistent density of $10^{9} \mathrm{CFU} / \mathrm{mL}$ of cells. Next, 100 $\mu \mathrm{L}$ of the pre-culture was transferred to one side of a stainless steel coupon (hairline finish, $50 \times 50 \times 1 \mathrm{~mm}$, Type 304; Supreme Steelmakers Sdn Bhd, Kuala Lumpur,
Malaysia)) and placed in pre-sterilized plastic containers $(50 \times 50 \times 30 \mathrm{~mm})$. Stainless steel coupons and containers were previously washed using dishwashing detergent, sonicated (Powersonic 420; Hwashin Technology, Seoul, Korea) for $20 \mathrm{~min}$, and soaked in $90 \%$ ethanol (Merck) for $1 \mathrm{~h}$, followed by autoclaving (HVE50; Hirayama Manufacturing Corporation, Saitama, Japan) at $121^{\circ} \mathrm{C}$ for $15 \mathrm{~min}$. The stainless steel coupons (Type 304; Supreme Steelmakers Sdn Bhd) in the plastic container were subjected to UV sterilization for $15 \mathrm{~min}$ prior to the transfer procedure. An amount of $100 \mu \mathrm{L}$ of the culture was placed on the sterile stainless steel in the plastic container and covered for incubation at $30^{\circ} \mathrm{C}$ for $48 \mathrm{~h}$.

Bacterial and biofilm transfer The stainless steel coupons in the sterile plastic container were covered with a lid and placed in an incubator (Sanyo MIR253; Sanyo Electric Biomedical Corporation Ltd., Osaka, Japan) at $30^{\circ} \mathrm{C}$ for $48 \mathrm{~h}$. The transfer procedure was conducted in a sterile environment. Initial counts of cells attached to the stainless steel coupons were made prior to the transfer procedure using the plate spreading procedure on PALCAM agar (Merck) with 1\% crystal violet (Merck) staining Conditions were designed to mimic a contaminated surface used for packing foods in plastics. Plastic wrappers that were previously sterilized with soaking in $70 \%$ ethanol (Merck) and UV for $30 \mathrm{~min}$ measuring $50 \times 50 \mathrm{~mm}$ were placed on the surface of the stainless steel coupons under pressure using weights of $0.1,0.2,0.3,0.4$, and $0.5 \mathrm{~kg}$ for $30 \mathrm{~s}$. The individual weights were prepared using plastic bags containing water to ensure full contact between surfaces during pressurization based on water flow in the plastic bags. Surfaces of the plastic bag weights were sterilized using $70 \%$ ethanol (Merck) prior to use. The simulated transfer material was then subjected to the spread plating with crystal violet (Merck) staining for enumeration after bacterial transfer from the stainless steel surface to the plastic wrap. Experiments were conducted in triplicate and repeated twice.

Calculation of compression due to weights was based on the weight applied to the plastic wrapper and the stainless steel. Determination of the effective transfer rate based on the pressure applied was performed using the following calculation (21):

$$
\begin{aligned}
& \text { Transfer rate (\%) } \\
& =\frac{\text { Number of CFU on plastic }}{\text { Initial number of CFU on stainless steel }} \times 100
\end{aligned}
$$

Enumeration of colonies Enumeration of bacterial contamination on the plastic wrappers and stainless steel coupons was conducted by putting the materials into a sterile stomacher (BagLight Model L; Interscience, St. 
Nom la Breteche, France) containing $10 \mathrm{~mL}$ of buffered peptone water (Merck), followed by mixing the materials by scrubbing the surface against the bag to dislodge the attached cells and colonies, and vigorous shaking of the suspended colonies by hand for $10 \mathrm{~s}$. Then, $1 \mathrm{~mL}$ of the broth from the bag was diluted using buffered peptone water (Merck) followed by plating on PALCAM agar (Merck). Plates were incubated at $30^{\circ} \mathrm{C}$ for $48 \mathrm{~h}$ prior to a colony count.

Biofilm readings The crystal violet staining procedure was carried out with slight modification of the method of Djordjevic et al. (22). Briefly, abiotic surfaces were rinsed with running sterile distilled water (Elga Purelab Classic UVMK2; ELGA LabWater, High Wycombe, UK) for $30 \mathrm{~s}$, then stained with $1 \mathrm{~mL}$ of $1 \%$ crystal violet (Merck) that was filter sterilized using $0.2 \mu \mathrm{m}$ syringe filter (Minisart; Sartorius AG, Goettingen, Germany). The crystal violet solution was allowed to stand on the contact surfaces for $20 \mathrm{~min}$, followed by rinsing under running water using sterile distilled water (ELGA Option-S 78P; ELGA LabWater) The abiotic surfaces were dried in a laminar hood (Esco AVC-4A1; ESCO Technologies, Inc., Hatboro, PA, USA) for $1 \mathrm{~h}$, then a total of $5 \mathrm{~mL}$ of $95 \%$ absolute ethanol (Merck) was added to elute the crystal violet (Merck). Reading of biofilms was carried out using a spectro-photometer (Spectrophotometer 170-6930; Bio-Rad, Hercules, CA, USA) at $570 \mathrm{~nm}$ with an appropriate blank and baseline. Preparation of blank was based on the elution of crystal violet using 95\% absolute ethanol (Merck) and baseline was the negative control to ensure the stainless steel does not affect the absorbance reading of crystal violet. Results were obtained and presented as mean values and standard deviations of absorbance readings.

Statistical analysis An analysis of variance (ANOVA) was performed to identify significant differences between means. Analysis used the SPSS version 17.0 software package (SPSS Institute, Cary, NC, USA). Statistical significance was defined as $p<0.05$.

\section{Results and Discussion}

The initial number of cells on the stainless steel surface was a mean value of $9.51 \log \mathrm{CFU} / \mathrm{mL}$ with a mean absorbance $\left(\mathrm{A}_{570 \mathrm{~mm}}\right)$ value of 0.654 using crystal violet staining. Formation of L. monocytogenes biofilms can occur with various counts and under on various surfaces, such as on Buna-N rubber (23), at a level of $2.1 \log$ CFU/ $\mathrm{cm}^{2}$ on $0.8 \%$ minimal $\mathrm{NaCl}$ medium (24), and on glass and steel surfaces (25). The experimental conditions of this study favored formation of a biofilm on stainless steel after $48 \mathrm{~h}$. Serotype $1 / 2 \mathrm{a}$ is commonly isolated from food so emphasis on this serotype can deepen our understanding of cross contamination of foods.

Contamination of $L$. monocytogenes was found to be independent of the pressure applied to the contact surface between stainless steel and plastic. Results (mean and standard deviation values) for biofilm density $\left(\mathrm{A}_{570}\right)$ showed no significant $(p>0.05)$ (Table 1) effect for pressure on the transferred $\log \mathrm{CFU} / \mathrm{mL}$ value or on absorbance values of the stainless steel or plastic surfaces between the weights applied. A cell count of approximately 2.5-3.6 log CFU/ $\mathrm{mL}$ was obtained for the plastic after transfer from stainless steel at an original steel contamination level of (mean) 9.51 $\log$ CFU/mL (Table 1). The percentage of cells transferred to the plastic surface was not proportional to the weight applied, with a transfer rate range in the range of 24 to $35 \%$ to the plastic surface. These percentage values can be considered as a range for uniform transfer of biofilm cells (CFU/mL) for contact between two types of dry surface.

Previous studies have identified factors involved in transfer of biofilm bacterial cells from surfaces. Montville and Schaffner (26) reported a connection between the inoculum size and the percent transfer rate in cross contamination activities. The bacterial transfer rate remained constant even though there was an increase in the initial inoculum size. Different inoculum sizes were investigated in relation to the number of cells transferred and found that a constant transfer rate led to a decrease in the percent of transfer rate in the cross contamination study (26), which

Table 1. Means and standard deviations for cell and colony transfer from a biofilm to plastic wrappers based on applied weights

\begin{tabular}{cccc}
\hline \multirow{2}{*}{ Weight $\left(\mathrm{kg} / \mathrm{m}^{3}\right)$} & \multicolumn{3}{c}{ Plastic wrapper (mean \pm SD) } \\
\cline { 2 - 4 } & Absorbance & CFU/mL & Percentage of transfer \\
\hline 40 & $0.221 \pm 0.01$ & $3.295 \pm 0.68$ & $34.2 \pm 6.18$ \\
80 & $0.277 \pm 0.03$ & $3.649 \pm 0.67$ & $35.2 \pm 5.78$ \\
120 & $0.271 \pm 0.01$ & $2.623 \pm 0.64$ & $27.1 \pm 6.07$ \\
160 & $0.317 \pm 0.05$ & $3.335 \pm 0.58$ & $34.6 \pm 5.56$ \\
200 & $0.282 \pm 0.05$ & $2.511 \pm 0.82$ & $24.9 \pm 8.29$ \\
\hline Statistical Analysis & & & ND $^{1)}$ \\
ANOVA (F; $p<0.05)$ & $0.853 ; 0.5$ & $0.52 ; 0.721$ & \\
\hline
\end{tabular}

${ }^{11} \mathrm{ND}$, not detected 
was similar to findings of a constant transfer rate in this study. However, Vorst et al. (27), in a study of transfer of L. monocytogenes in mechanical slicing of turkey breast, bologna, and salami, reported significant transfer of Listeria when a force of $4.5 \mathrm{~kg}$ was placed on samples, compared with no weight. Contamination of non-spore producers can readily occur via contact between wet sponges, stainless steel surfaces, and food (21). Contamination of pathogens with pressure ranged from 30 to $100 \%$ for Staphylococcus aureus, Salmonella enteritidis, and Campylobacter jejuni. Transfer of these pathogens from stainless steel to food was affected by the pressure applied.

The concentrations of moisture and fats in food, compared with dry plastic surfaces, may be related to contrasting results. Smooth plastic surfaces may not provide a favorable medium for bacterial transfer of Listeria. Another transfer factor is the surface condition (dry/moist) as transfer can occur more easily on moist surfaces (26). The previous study of Vorst et al. (27) regarding the effect of weight used application of $4.5 \mathrm{~kg}$ of force for transfer of Listeria. This study used increments of $0.1 \mathrm{~kg}$ of force, which may not have been sufficient for transfer of Listeria between the surfaces. Transfer of cells and colonies from a bacterial biofilm is largely affected by the medium for transfer, particularly for foods with high fat and moisture contents. Therefore, when transfer between dry abiotic surfaces was studied in the present work, the effect of weight does not facilitate the transfer between the contact surfaces.

Chavant et al. (28) reported that L. monocytogenes forms biofilms more rapidly on hydrophilic surfaces than on hydrophobic surfaces, compared to other typical microorganisms, probably due to interactions between the cell surface and environmental surfaces that enable cells to overcome repulsive forces and attach irreversibly (29). Hydrophilic surfaces are common in the food preparation environment, and contamination and subsequent adherence of pathogens to surfaces can occur if a good cleaning procedure is not practiced (30). Hansen et al. (30) reported a significant improvement in the survival of desiccated cells in a biofilm, compared to non-biofilm cells, for transfer to salmon slices. The efficiency of transfer was significantly affected by the presence of the biofilm that aided cell survival in a desiccated form, and subsequent transfer to food. This study focused on abiotic surfaces. The potential of food contamination $(\mathrm{CFU} / \mathrm{mL})$ that is higher than the initial contamination on a surface exists due to revival of injured, non-laboratory-cultivable cells that subsequently act to increase the rate of cross-contamination along the processing line (30).

Contamination of L. monocytogenes can be an important consequence for food safety. Estimation of transfer rates based on contact weight may be an interesting focus for providing data for microbiological risk assessments, such as application of a uniform distribution represented by (minimum 24.9; maximum 35.2) for cross contamination modeling between two surfaces. This is the first study to report cross contamination of biofilm transfer between abiotic surfaces based on a contact pressure series. Application of findings in this study can be used for estimating the risk involved in cross contamination of foods at the factory level when biofilms are involved. A biofilm is a complex structure that plays an important role in persistence of microorganisms. Many other factors should also be included in estimation of cross contamination.

Acknowledgments This research was funded by Ministry of Health, Malaysia, and supported in part by a Grant-in Aid for Scientific Research (KAKENHI 191010) from the Japan Society for the Promotion of Sciences.

Disclosure The authors declare no conflict of interest.

\section{References}

1. Gillespie IA, McLauchlin J, Grant KA, Little CL, Mithani V, Penman C, Lane C, Regan M. Changing pattern of human listeriosis, England and Wales, 2001-2004. Emerg. Infect. Dis. 2006. 12: 1361-1366 (2006)

2. Denny J, McLauchlin J. Human Listeria monocytogenes infections in Europe--an opportunity for improved European surveillance. Euro surveillance: Bulletin européen sur les maladies transmissibles. Eur. Commun. Dis. Bullet. 13: 1854-1861 (2008)

3. Jensen AK, Ethelberg S, Smith B, Nielsen EM, Larsson J, Mølbak K, Christensen J, Kemp M. Substantial increase in listeriosis, Denmark 2009. Euro. Surveill. 15: 19522 (2010)

4. Mead PS, Slutsker L, Dietz V, McCaig LF, Bresee JS, Shapiro C, Griffin PM, Tauxe RV. Food-related illness and death in the United States. Emerg. Infect. Dis. 5: 607-625 (1999)

5. Kathariou S. Listeria monocytogenes virulence and pathogenicity, a food safety perspective. J. Food Prot. 65: 1811-1829 (2002)

6. Reij M, Den Aantrekker E. Recontamination as a source of pathogens in processed foods. Int. J. Food Microbiol. 91: 1-11 (2004)

7. Gianfranceschi M, Gattuso A, Tartaro S, Aureli P. Incidence of Listeria monocytogenes in food and environmental samples in Italy between 1990 and 1999: Serotype distribution in food, environmental and clinical samples. Eur. J. Epidemiol. 18: 1001-1006 (2003)

8. Zottoia E. Microbial attachment and biofilm formation: A new problem for the food industry? Food Technol. 48: 107-114 (1994)

9. Chmielewski R, Frank J. Biofilm formation and control in food processing facilities. Comp. Rev. Food Sci. Food Safety. 2: 22-32 (2003)

10. Brooks JD, Flint SH. Biofilms in the food industry: Problems and potential solutions. Int. J. Food Sci. Technol. 43: 2163-2176 (2008)

11. Bower C, McGuire J, Daeschel M. The adhesion and detachment of bacteria and spores on food-contact surfaces. Trends Food Sci. Tech. 7: 152-157 (1996)

12. Hood SK, Zottola EA. Isolation and identification of adherent gramnegative microorganisms from four meat-processing facilities. J. Food Prot. 60: 1135-1138 (1997)

13. Beresford M, Andrew P, Shama G. Listeria monocytogenes adheres to many materials found in foodprocessing environments. J. Appl. Microbiol. 90: 1000-1005 (2001)

14. Arnold J, Bailey G. Surface finishes on stainless steel reduce bacterial attachment and early biofilm formation: Scanning electron 
and atomic force microscopy study. Poultry Sci. 79: 1839-1845 (2000)

15. Rodriguez A, Autio WR,McLandsborough LA. Effect of surface roughness and stainless steel finish on Listeria monocytogenes attachment and biofilm formation. J. Food Prot. 71: 170-175 (2008)

16. Thévenot D, Delignette-Muller ML, Christieans S, Vernozy-Rozand C. Prevalence of Listeria monocytogenes in 13 dried sausage processing plants and their products. Int. J. Food Microbiol. 102: 85-94 (2005)

17. Chaitiemwong N, Hazeleger W, Beumer R. Survival of Listeria monocytogenes on a conveyor belt material with or without antimicrobial additives. Int. J. Food Microbiol. 142: 260-263 (2010)

18. Gjermansen M, Ragas P, Sternberg C, Molin S, TolkerNielsen T. Characterization of starvationinduced dispersion in Pseudomonas putida biofilms. Environ. Microbiol. 7: 894-904 (2005)

19. Sauer K, Cullen M, Rickard A, Zeef L, Davies D, Gilbert P. Characterization of nutrient-induced dispersion in Pseudomonas aeruginosa PAO1 biofilm. J. Bacteriol. 186: 7312-7326 (2004)

20. Thormann KM, Saville RM, Shukla S, Spormann AM. Induction of rapid detachment in Shewanella oneidensis MR-1 biofilms. J. Bacteriol. 187: 1014-1021 (2005)

21. Kusumaningrum HD, Riboldi G, Hazeleger WC, Beumer RR. Survival of foodborne pathogens on stainless steel surfaces and cross-contamination to foods. Int. J. Food Microbiol. 85: 227-236 (2003)

22. Djordjevic D, Wiedmann M, McLandsborough L. Microtiter plate assay for assessment of Listeria monocytogenes biofilm formation. Appl. Environ. Microbiol. 68: 2950-2958 (2002)
23. Ronner $\mathrm{AB}$, Wong $\mathrm{A}$. Biofilm development and sanitizer inactivation of Listeria monocytogenes and Salmonella typhimurium on stainless steel and Buna-n rubber. J. Food Prot. 56: 750-758 (1993)

24. Lee HY, Chai LC, Pui CF, Mustafa S, Cheah YK, Nishibuchi M, Radu S. Formation of biofilm by Listeria monocytogenes ATCC 19112 at different incubation temperatures and concentrations of sodium chloride. Braz. J. Microbiol. 44: 51-55 (2013)

25. Di Bonaventura G, Piccolomini R, Paludi D, D’orio V, Vergara A, Conter M, Ianieri A. Influence of temperature on biofilm formation by Listeria monocytogenes on various foodcontact surfaces: relationship with motility and cell surface hydrophobicity. J. Appl. Microbiol. 104: 1552-1561 (2008)

26. Montville R, Schaffner D. Inoculum size influences bacterial cross contamination between surfaces. Appl. Environ. Microbiol. 69: $7188-7193$ (2003)

27. Vorst KL, Todd EC, Ryser ET. Transfer of Listeria monocytogenes during mechanical slicing of turkey breast, bologna, and salami. J. Food Prot. 69: 619-626 (2006)

28. Chavant P, Martinie B, Meylheuc T, Bellon-Fontaine M-N, Hebraud M. Listeria monocytogenes LO28: Surface physicochemical properties and ability to form biofilms at different temperatures and growth phases. Appl. Environ. Microbiol. 68: 728-737 (2002)

29. Donlan RM, Donlan R. Biofilms: Microbial life on surfaces. Emerg. Infect. Dis. 8: 881 (2002)

30. Hansen LT, Vogel BF. Desiccation of adhering and biofilm Listeria monocytogenes on stainless steel: Survival and transfer to salmon products. Int. J. Food Microbiol. 146: 88-93 (2011) 